\title{
Thirty-day postoperative morbidity and mortality after temporal lobectomy for medically refractory epilepsy
}

\author{
Panagiotis Kerezoudis, MD, 1,2 Brandon McCutcheon, MD, MPP, 1,2 Meghan E. Murphy, MD,1,2 \\ Kenan R. Rajjoub, BA, ${ }^{3}$ Daniel Ubl, MPH, ${ }^{4}$ Elizabeth B. Habermann, PhD, MPH, ${ }^{4}$ \\ Gregory Worrell, MD, PhD, ${ }^{5}$ Mohamad Bydon, MD, ${ }^{1,2}$ and Jamie J. Van Gompel, MD1
}

\begin{abstract}
${ }^{1}$ Department of Neurologic Surgery, ${ }^{2}$ Mayo Clinic Neuro-Informatics Laboratory, ${ }^{4}$ Mayo Clinic Robert D. and Patricia E. Kern Center for the Science of Health Care Delivery, and ${ }^{5}$ Department of Neurology, Mayo Clinic, Rochester, Minnesota; and ${ }^{3}$ George Washington University, Washington, DC
\end{abstract}

\begin{abstract}
OBJECTIVE Temporal lobectomy is a well-established treatment modality for the management of medically refractory epilepsy in appropriately selected patients. The aim of this study was to assess 30 -day morbidity and mortality after temporal lobectomy in cases registered in a national database.
\end{abstract}

METHODS A retrospective cohort analysis was conducted using a multiinstitutional surgical registry compiled between 2006 and 2014. The authors identified patients who underwent anterior temporal lobectomy and/or amygdalohippocampectomy for a primary diagnosis of intractable epilepsy. Univariate and multivariable analyses with regard to patient demographics, comorbidities, operative characteristics, and 30-day outcomes were applied.

\begin{abstract}
RESULTS A total of 216 patients were included in the study. The median age was 38 years and $46 \%$ of patients were male. The median length of stay was 3 days and the 30 -day mortality rate was $1.4 \%$. Fourteen patients (6.5\%) developed at least one major complication. Return to the operating room was observed in 7 patients (3.2\%). Readmission within 30 days and discharge to a location other than home were available for 2011-2014 $(n=155)$ and occurred in $11 \%$ and $10.3 \%$ of patients, respectively. Multivariable regression analysis revealed that increasing age was an independent predictor of discharge disposition other than home and that male sex was a significant risk factor for the development of a major complication. Interestingly, the presence of the attending neurosurgeon and a resident during the procedure was significantly associated with decreased odds of prolonged length of stay (i.e., > 75th percentile [5 days]) and discharge to a location other than home.
\end{abstract}

CONCLUSIONS Using a multiinstitutional surgical registry, 30-day outcome data after temporal lobectomy for medically intractable epilepsy demonstrates a mortality rate of $1.4 \%$, a major complication rate of $6.5 \%$, and a readmission rate of $11 \%$. Temporal lobectomy is an extremely effective therapy for seizures originating there-however, surgical intervention must be weighed against its morbidity and mortality outcomes.

https://thejns.org/doi/abs/10.3171/2016.12.JNS162096

KEY WORDS epilepsy surgery; temporal lobectomy; amygdalohippocampectomy; NSQIP; National Surgical Quality Improvement Program

$\mathrm{A}$ PPROXIMATELY one-third of the 3 million people with epilepsy in the US continue to have seizures despite taking antiseizure medications (ASMs). ${ }^{5}$ Once medically intractable seizures are established (failure of 2 ASMs at reasonable dosing to control seizures), patients are evaluated for surgical intervention. Surgical therapy represents an important yet underutilized treatment in patients with medically refractory epilepsy, despite the existence of Class I evidence advocating the efficacy and safety of resective surgery in a selected population. ${ }^{6,8,21,37}$

Seizures arising from the temporal lobe represent the most common form of epilepsy and are the most likely to remain refractory to antiepileptic medication. ${ }^{3,7}$ It has been estimated that approximately 300-500 cases of anterior

ABBREVIATIONS ACS = American College of Surgeons; ASA = American Society of Anesthesiologists; $A S M=$ antiseizure medication; $A T L=$ anterior temporal lobectomy; $\mathrm{BMI}=$ body mass index; CPT = Current Procedural Terminology; DVT = deep vein thrombosis; ICD-9 = International Classification of Diseases, 9th Revision; LOS = length of stay; MI = myocardial infarction; NIS = Nationwide Inpatient Sample; NSQIP = National Surgical Quality Improvement Program; PUF = Participant User File; TLE = temporal lobe epilepsy; UTI = urinary tract infection.

SUBMITTED August 11, 2016. ACCEPTED December 21, 2016.

INCLUDE WHEN CITING Published online June 23, 2017; DOI: 10.3171/2016.12.JNS162096. 
temporal lobectomy (ATL) and selective amygdalohippocampectomy for intractable epilepsy are performed annually in the US. ${ }^{10}$ Moreover, a recent article by Englot and colleagues demonstrated that hospital and surgeon volume $(<15$ lobectomies/year) is a significant predictor of perioperative morbidity in patients undergoing surgery. ${ }^{11}$

Although the perioperative outcomes after ATL have been extensively studied in single-institution series, there is a paucity of larger-scale studies concerning complications associated with temporal lobe surgery for epilepsy (Table 1). We sought to fill this void in the literature by examining 30-day postoperative morbidity and mortality outcomes following temporal lobectomy for intractable epilepsy by using a multiinstitutional, national surgical registry.

\section{Methods \\ Data Source}

The American College of Surgeons National Surgical Quality Improvement Program (ACS-NSQIP) for the years 2006 through 2014 was queried for this retrospective cohort analysis. The NSQIP data set contains more than 300 variables on patient demographics, comorbidities, and intraoperative data as well as 30-day postoperative morbidity and mortality outcomes. ${ }^{18}$ The registry has grown significantly since its inception in 2001. By December 2008, almost 200 hospitals were contributing data and were receiving real-time, risk-adjusted feedback on their surgical outcomes.$^{29}$ Currently, the data set holds information on more than 1.7 million patients from more than 500 hospitals, $58 \%$ of which are large academic institutions. ${ }^{23}$ In addition, the majority of the data represent a random sample of all procedures performed by the various surgical subspecialties. ${ }^{29}$ Data acquisition at each participating institution is carried out by specialized data collectors, who undergo extensive training. More importantly, interrater reliability audits by Surgical Clinical Reviewers and quality control processes ensure that data are collected and maintained with high fidelity. According to the most recent report, the interrater reliability audit for participating sites revealed an overall disagreement rate of approximately $2 \%{ }^{1}$ The study was exempt from review by our institutional review board, because the ACS-NSQIP contains deidentified data.

\section{Inclusion and Exclusion Criteria}

Patients with intractable epilepsy were identified using the Current Procedural Terminology (CPT) codes designating temporal lobe surgery (61537: craniotomy with elevation of bone flap for lobectomy, temporal lobe, without electrocorticography during surgery; 61538: craniotomy with elevation of bone flap for lobectomy, temporal lobe, with electrocorticography during surgery; and 61566: craniotomy with elevation of bone flap for selective amygdalohippocampectomy) in combination with a primary postoperative International Classification of Diseases, 9th Revision (ICD-9) diagnosis code of epilepsy (345.1-345.9). Exclusion criteria included prior chemotherapy within 30 days, radiotherapy within 90 days, sepsis, history of disseminated cancer, emergency surgery, and prior operation within 30 days, such as subdural grid placements. Therefore, our patient cohort consisted of temporal lobectomy cases with or without intraoperative electrocorticography performed at the same procedure; however, this excludes staged extraoperative intracranial monitoring.

\section{Postoperative Events of Interest}

The primary outcome of interest was mortality within the 30-day postoperative period. Secondary outcomes included the development of any minor or major complication. Major complications included wound dehiscence, deep surgical site infection, organ space infection, pneumonia, reintubation, pulmonary embolism, failure to wean ventilatory support within 48 hours of surgery, renal failure, renal insufficiency, stroke, coma, nerve injury, cardiac arrest, myocardial infarction (MI), sepsis, septic shock, and return to the operating room within 30 days of surgery. Minor complications included deep vein thrombo-

TABLE 1. Population-based published studies on lobectomy for intractable epilepsy in adults

\begin{tabular}{|c|c|c|c|c|c|}
\hline Authors \& Year & $\begin{array}{l}\text { Data } \\
\text { Source }\end{array}$ & $\begin{array}{l}\text { Years of } \\
\text { Study }\end{array}$ & $\begin{array}{l}\text { No. of } \\
\text { Pts }\end{array}$ & Outcome of Interest & Finding \\
\hline Englot et al., 2012 & NIS & $1990-2008$ & 6653 & Time trends of surgery in the US & Despite Class I evidence, the use of lobectomy has not increased \\
\hline $\begin{array}{l}\text { Schiltz et al., } \\
2013\end{array}$ & NIS & $1998-2003$ & 2642 & Trends in preop evaluation & $\begin{array}{l}\text { Significant increase in VEEG monitoring but not IEEG monitoring } \\
\text { or surgery }\end{array}$ \\
\hline $\begin{array}{l}\text { McClelland et al., } \\
2010\end{array}$ & NIS & $1988-2003$ & 562 & Racial disparities & $\begin{array}{l}\text { Younger pts \& those w/ private insurance more likely to receive } \\
\text { ATL; African Americans less likely to receive ATL }\end{array}$ \\
\hline $\begin{array}{l}\text { McClelland et al., } \\
2011\end{array}$ & NIS & $1988-2003$ & 736 & Morbidity \& mortality & Mortality: 0\%; overall complications: $8 \%$; adverse discharge: $4 \%$ \\
\hline Englot et al., 2013 & NIS & $1990-2008$ & 6652 & $\begin{array}{l}\text { Relationship btwn surgical vol \& } \\
\text { adverse periop events }\end{array}$ & $\begin{array}{l}\text { Incidence of periop adverse events was significantly higher in } \\
\text { low-vol centers }(12.9 \% \text { vs } 6.1 \% ;<15 \text { lobectomies/yr) }\end{array}$ \\
\hline $\begin{array}{l}\text { Koubeissi et al., } \\
2009\end{array}$ & NIS & $2000-2005$ & 484 & $\begin{array}{l}\text { Complications after IE implanta- } \\
\text { tion \& lobectomy }\end{array}$ & $\begin{array}{l}\text { Hemorrhage \& status epilepticus risk was higher in IE group } \\
\text { compared to lobectomy }\end{array}$ \\
\hline $\begin{array}{l}\text { Van Gompel et } \\
\quad \text { al., } 2012\end{array}$ & REP & $1993-2009$ & 847 & $\begin{array}{l}\text { Changes in ATL over time by } \\
\text { sex }\end{array}$ & $\begin{array}{l}\text { The rate of ATL was } 1.6 \& 0.7 \text { per } 100,000 \text { person-yrs for female } \\
\text { \& male pts, respectively }\end{array}$ \\
\hline
\end{tabular}

$\mathrm{IE}=$ intracranial electrode; IEEG = intraoperative electroencephalography; pts = patients; REP = Rochester Epidemiology Project; VEEG = video electroencephalography. 
sis (DVT), urinary tract infection (UTI), and superficial surgical site infection. Last, we investigated length of stay (LOS) and discharge to a location other than home (skilled care, rehabilitation facility, or unskilled care) as well as 30-day readmission and reoperation. Discharge destination and readmission are available beginning in the 2011 Participant User File (PUF).

\section{Covariates}

The covariates of interest included the following: age, race, sex, body mass index (BMI), total operating time in minutes, patient functional status, physical status classification as described by the American Society of Anesthesiologists (ASA) (Table 2), smoking status, history of diabetes, hypertension requiring medication, congestive heart failure, history of severe chronic obstructive pulmonary disease, dyspnea either with activity or at rest, bleeding disorder, presence of a CNS tumor (available from 2005 through 2012), and history of chronic corticosteroid use within 30 days of the operation. ${ }^{26} \mathrm{We}$ also documented resident participation during the case by using the "ATTEND" variable. According to the NSQIP PUF, the ATTEND variable reflects the highest level of residency supervision by the attending staff surgeon for the case. "Attending alone" means that a staff practitioner performed the procedure and a resident was not present, whereas "Attending \& Resident in the OR" means that a staff practitioner and a resident performed the case. Other possible values include "Attending Not Present, but Available," which means that a staff practitioner was not present, but was immediately available on campus. This variable has been available from 2005 through 2012 (because it was a classic variable, beginning in 2013, no NSQIP participating institutions collected the variable).

\section{Statistical Analysis}

Statistical analysis was performed using open-source software (R Core Team [2015]. R: A language and environment for statistical computing. https://www.R-project.org/). Continuous variables were compared using the Student ttest and Wilcoxon-Mann-Whitney test. Categorical variables were compared using the chi-square and Fisher exact test. Due to the very low number of patients in ASA Class IV $(n=3)$, we categorized patients with ASA Class III or greater as high ASA class, and Class I or II as low ASA class. The statistical significance level was established at $\mathrm{p}=0.05$.

Imputation was applied to correct for missing variables. Missing values in the data were imputed using the "missForest" R package, a nonparametric multiple imputation method based on the random forest algorithm..$^{4,35}$ Briefly, for each variable with missing values in the data, missForest fits a random forest model on the observed part and then predicts the missing part. The algorithm iterates over these 2 steps until a stopping criterion is met or a maximum number of iterations is reached. The stopping criterion is met when the difference between the current imputed data and the previous one increases. Differing from traditional multiple imputation methods, missForest can handle high-dimensional data sets with mixed-type variables (continuous, categorical, counts, and so on), nonlinear relationships, and complex interactions. In the imputed data sets, multivariable regression analysis was fitted for outcomes with an occurrence rate greater than 5\%; i.e., any major complication, discharge disposition, and 30-day readmission, as well as for prolonged LOS. Multivariable models controlled for available patient and operative variables. The results presented are the pooled estimates from the analysis on each of the imputed data sets. Where age was found to be an independent predictor, we classified it as a categorical variable based on quintiles. As a result, the following categories were created: $18-30,31-45,46-55$, 56-65, and 66-78 years. This classification allowed us to identify the age groups at increased risk for postoperative adverse events.

\section{Results}

A total of 216 patients were identified in the ACS-NSQIP data set as having received temporal lobectomy (ATL: 177 patients; selective amygdalohippocampectomy: 39 patients) for intractable epilepsy between 2006 and 2014. Patient demographic data and comorbidities are presented in Table 3.

Within this cohort, the median age was 38 years (range

TABLE 2. Categories of ASA classification

\begin{tabular}{|c|c|c|}
\hline $\begin{array}{c}\text { ASA } \\
\text { Category }\end{array}$ & Description & Examples \\
\hline Class I & Normal healthy patient & Healthy, no smoking or drinking, good exercise tolerance \\
\hline Class II & Patients with mild systemic disease & $\begin{array}{l}\text { Obesity }(30<\mathrm{BMI}<40) \text {, current smoker, pregnancy, well-controlled } \\
\text { DM or HTN }\end{array}$ \\
\hline Class III & Patients with severe systemic disease & Morbid obesity (BMI $\geq 40$ ), poorly controlled DM or HTN, alcohol abuse \\
\hline Class IV & Patients with severe systemic disease that is constant threat to life & Recent MI or CVA (<3 mos), sepsis, symptomatic CHF/COPD \\
\hline Class V & $\begin{array}{l}\text { Moribund patients who are not expected to survive without the } \\
\text { operation }\end{array}$ & $\begin{array}{l}\text { Not expected to survive more than } 24 \text { hours without surgery, ruptured } \\
\text { thoracic or abdominal aneurysm }\end{array}$ \\
\hline Class VI & $\begin{array}{l}\text { A declared brain-dead patient whose organs are being removed } \\
\text { for donor purposes }\end{array}$ & \\
\hline
\end{tabular}

$\mathrm{CHF}$ = congestive heart failure; $\mathrm{COPD}=$ chronic obstructive pulmonary disease; $\mathrm{CVA}=$ cerebrovascular accident; $\mathrm{DM}=$ diabetes mellitus; $\mathrm{HTN}=$ hypertension. Based on ASA Physical Status Classification System (2014) of the American Society of Anesthesiologists. A copy of the full text can be obtained from ASA, 1061 American Lane, Schaumburg, IL 60173-4973, or online at www.asahq.org. 
TABLE 3. Demographic and comorbidity data in patients with TLE

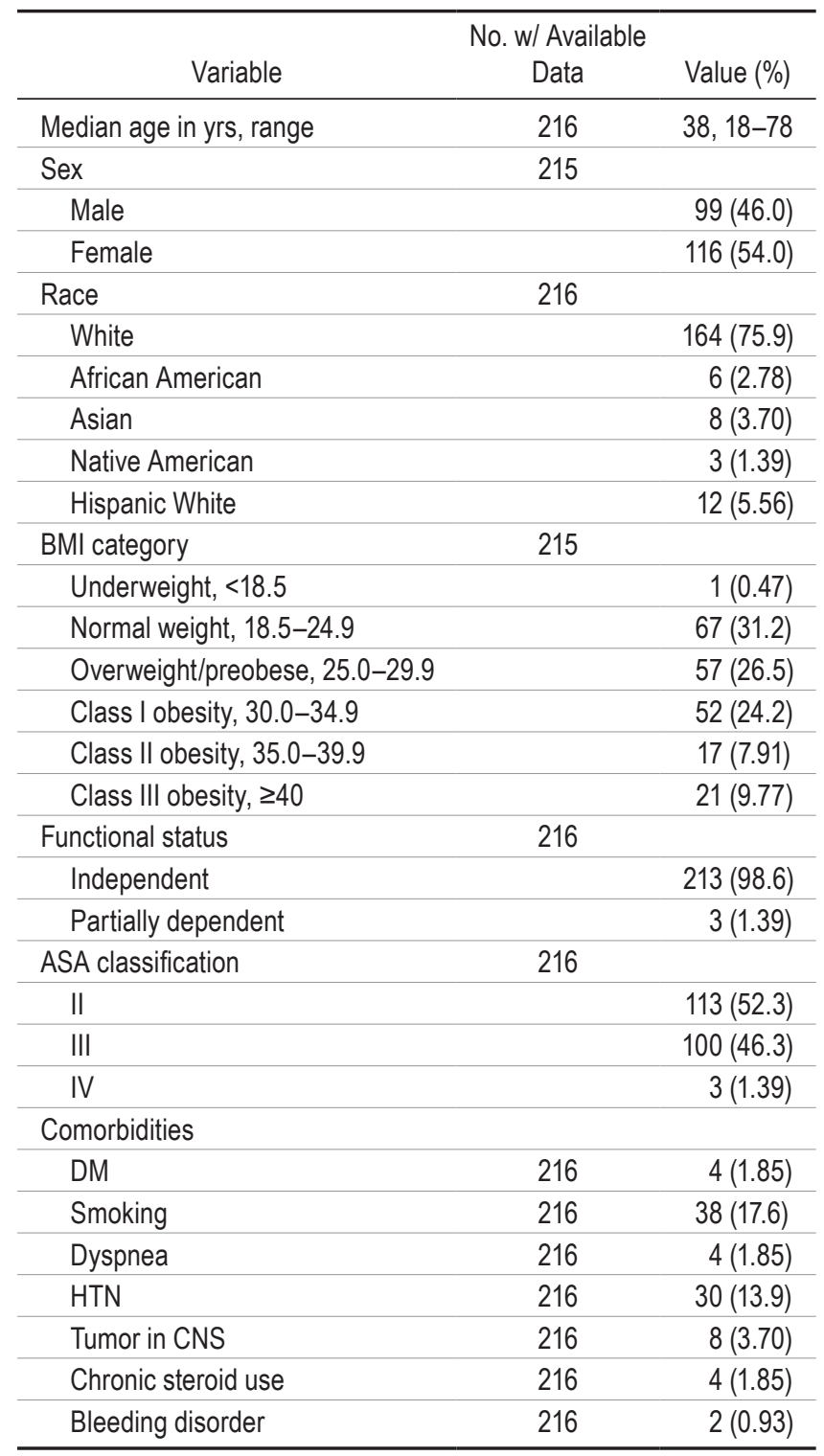

$18-78$ years) and $46 \%$ of patients were male. The mortality rate during the 30 -day postoperative period was $1.39 \%$ (Table 4). The median operating time was 241.5 minutes (range 140-534 minutes) and the median LOS was 3 days (range 1-22 days). Prolonged LOS, defined as a stay greater than the 75th percentile (5 days), was observed in 43 patients $(19.9 \%)$. Fourteen patients $(6.48 \%)$ experienced at least one of the following major complications: sepsis or septic shock (0.93\%), stroke (1.39\%), organ space infection $(1.39 \%)$, deep incisional surgical site infection $(0.46 \%)$, wound dehiscence $(0.93 \%)$, reintubation $(0.46 \%)$, cardiac arrest $(0.46 \%)$, or MI $(0.46 \%)$. Minor complications occurred at the following rates: DVT $(0.46 \%)$ and UTI $(0.93 \%)$. Moreover, reoperation within 30 days occurred in 7 patients (3.24\%). For patients admitted in 2011 or later $(\mathrm{n}=155)$, readmission within 30 days and discharge destination data were available for analysis. Within this cohort, 30 -day readmission occurred at a rate of $11 \%$. Last, 16
TABLE 4. Operative and postoperative data in patients with TLE

\begin{tabular}{|c|c|c|}
\hline Variable & $\begin{array}{c}\text { No. w/ } \\
\text { Available } \\
\text { Data }\end{array}$ & Value (\%) \\
\hline \multicolumn{3}{|l|}{ Operative data } \\
\hline Procedure & 216 & \\
\hline ATL & & $177(81.9)$ \\
\hline SA & & $39(18.1)$ \\
\hline Median op time in mins, range & 216 & $241.5,140-534$ \\
\hline Median LOS in days, range & 216 & $3,1-22$ \\
\hline Prolonged LOS* & 216 & $43(19.9)$ \\
\hline Surgeon & 115 & \\
\hline Attending alone & & $22(19.1)$ \\
\hline Attending \& resident & & $93(80.9)$ \\
\hline 30-day mortality & 216 & $3(1.39)$ \\
\hline Any major complication & & $14(6.48 \%) \dagger$ \\
\hline Sepsis/septic shock & 216 & $2(0.93)$ \\
\hline Stroke & 216 & $3(1.39)$ \\
\hline Organ space SSI & 216 & $3(1.39)$ \\
\hline Deep incisional SSI & 216 & $1(0.46)$ \\
\hline Wound dehiscence & 216 & $2(0.93)$ \\
\hline Cardiac arrest & 216 & $1(0.46)$ \\
\hline Reintubation & 216 & $1(0.46)$ \\
\hline Bleeding requiring transfusion & 216 & $1(0.46)$ \\
\hline Ml & 216 & $1(0.46)$ \\
\hline Any minor complication & & $2(0.93)$ \\
\hline UTI & 216 & $2(0.93)$ \\
\hline DVT & 216 & $1(0.46)$ \\
\hline Discharge destination & 155 & \\
\hline Home or home facility & & $139(89.68)$ \\
\hline $\begin{array}{l}\text { Other (skilled care, rehabilitation } \\
\text { facility, unskilled care) }\end{array}$ & & $16(10.32)$ \\
\hline 30-day readmission & 155 & $17(11.0)$ \\
\hline Return to the operating room & 216 & $7(3.24)$ \\
\hline
\end{tabular}

patients $(10.3 \%)$ were discharged to a location other than home.

On multivariable analysis (Table 5), increasing age was found to be an independent predictor of discharge disposition other than home (OR 1.06, 95\% CI 1.0031.13), and male sex was a significant risk factor for the development of a major complication (OR 5.53, 95\% CI 1.34-30.41). When we analyzed age as a categorical variable, we found that patients belonging to the 4th (56-65 years of age) and 5th (66-78 years of age) quintiles had significantly higher odds of adverse discharge disposition (OR 17.20, 95\% CI 1.71-25.31) and (OR 13.26, 95\% CI 1.08-19.83), respectively, compared with those between 18 and 30 years of age. Last, the presence of the attending neurosurgeon and a resident during the procedure was significantly associated with decreased odds of prolonged LOS; i.e., more than 5 days (OR 0.23 , $95 \%$ CI $0.08-0.68$ ) 
TABLE 5. Results of multivariable analysis for postoperative outcomes of interest in patients with TLE

\begin{tabular}{llc}
\hline \multicolumn{1}{c}{ Predictor Variable } & OR $(95 \% \mathrm{Cl})$ & $\begin{array}{c}\mathrm{p} \\
\text { Value }\end{array}$ \\
\hline Major complication & & \\
\hline Male sex vs female sex & $5.53(1.34-30.41)$ & $\mathbf{0 . 0 2 8}$ \\
\hline $\begin{array}{l}\text { Prolonged LOS } \\
\text { Attending \& resident in operating room } \\
\quad \text { vs attending alone }\end{array}$ & $0.23(0.08-0.68)$ & 0.007 \\
\hline $\begin{array}{l}\text { Discharge to destination other than home } \\
\text { Age }\end{array}$ & $1.06(1.003-1.13)$ & 0.042 \\
\hline $\begin{array}{l}\text { Attending \& resident in operating room } \\
\text { vs attending alone }\end{array}$ & $0.14(0.03-0.58)$ & $\mathbf{0 . 0 0 8}$ \\
\hline
\end{tabular}

Multivariable analysis after adjusting for the following variables: 1) age; 2) sex; 3) BMI; 4) smoking status; 5) ASA classification; 6) tumor in the CNS; 7) history of hypertension; 8) surgeon attendance in the operating room; 9) operating time.

Boldface type indicates statistical significance.

and decreased odds of discharge to a location other than home (OR 0.14, 95\% CI 0.03-0.58). No statistically significant predictors were identified on 30-day readmission adjusted analysis.

\section{Discussion}

Epilepsy is the second leading cause of mental disability in the US, and affects $0.5 \%-1 \%$ of the global population. The illness burden is similar to that experienced by lung and breast cancer patients., 9,18,21,27 Despite the evidence for the efficacy of temporal lobectomy in the management of medically refractory temporal lobe epilepsy (TLE) and the expanding use of neuroimaging and electroencephalographic studies in select patients who are likely to benefit, ${ }^{31}$ a large number of candidate patients are not referred for surgical evaluation. ${ }^{32,36,37}$ Several factors for the underutilization of temporal lobectomy include the fact that many patients are offered palliative surgical therapy, such as vagus nerve stimulation, or else endless medical therapies. Moreover, significant racial and socioeconomic disparities exist with regard to access to surgical intervention, with Medicare or Medicaid insured patients and African Americans being less likely to receive ATL. ${ }^{22}$

Our results confirm the work of previous authors who have looked at the risk factors associated with postoperative morbidity after temporal lobectomy for TLE. As in our study, increasing age is consistently correlated with unfavorable outcomes, including discharge disposition other than home, ${ }^{15,16,21,30}$ particularly for patients older than 55 years. Other reported factors in the literature that are associated with unfavorable postoperative outcomes include insurance status and nonroutine hospital admission. ${ }^{21}$ In addition to this, based on the results of the multivariable analysis, we found that male patients are at higher risk for postoperative morbidity compared with females. This observation has also been described in previous studies looking at morbidity and mortality after cranial neurosurgical procedures, and might be attributed to unmeasured confounding variables, such as the pathology of the lesion, which unfortunately are not available in the NSQIP. ${ }^{24,25}$ Alternatively, older male patients may have been less likely than younger adults to have a caregiver, and this in addition to other socioeconomic factors may have complicated discharge.

Interestingly, we found that patients who underwent operations in which both an attending and a resident neurosurgeon were present had significantly decreased hospital stays and odds of discharge to a location other than home. This may act as a surrogate of the academic nature of the hospital center, reflecting the higher hospital volume and increased specialty practice in epilepsy. In contrast to previous studies, we found a higher mortality rate in our patient cohort $(1.4 \%)$. This may be related to the fact that these were much older patients with a higher comorbidity burden. More likely, this represents the generalizability of this procedure to neurosurgical practice across private and academic setups, because individual case series may be biased toward better results and patient recruitment. However, the exact cause of death in these patients is not provided in the NSQIP PUF. Because ATL and amygdalohippocampectomy are invasive procedures, preoperative patient counseling should involve discussion of the increased mortality associated with nonsurgically treated, drug-resistant epilepsy ${ }^{33,34}$ as well as optimal risk stratification.

A recent systematic review conducted by Georgiadis and colleagues investigated the most common complications after TLE surgery. ${ }^{14}$ The authors found that mortality was $0 \%$ in all adult single-institution series. The cumulative complication rate (including neurological, surgical, and medical complications) ranged between $3 \%$ and $53 \%$. More specifically, the new postoperative neurological deficit (hemiparesis) rate was $1.7 \%-5 \%$, cranial nerve palsy was $2.6 \%-5 \%$, and aphasia was $1.7 \%-3.8 \%$. Last, DVTs and pulmonary embolism, when reported, were approximately $2 \%$. In our study, a major complication developed in $6.5 \%$ of patients, which is similar to the rate of $8 \%$ reported in a Nationwide Inpatient Sample (NIS) study. ${ }^{21}$

There is limited evidence on the morbidity and mortality profile after surgery for medically refractory TLE on a national scale. McClelland and colleagues identified 736 patients in the NIS who received ATL between 1988 and 2003. The rates for mortality, overall morbidity, and adverse discharge disposition were $0 \%, 8 \%$, and $4 \%$, respectively. ${ }^{21}$ The findings of our study corroborate current literature with regard to the low perioperative morbidity profile associated with TLE surgery. More importantly, our analysis included more recent years (i.e., 2006-2014), providing insight into the surgical outcomes of TLE surgery during the last decade. Temporal lobectomy should be viewed as a safe and effective procedure for patients with intractable TLE. Patients with few comorbidities should be referred for surgical evaluation in specialized centers, because it has been shown that high-volume hospitals have a significantly lower complication risk compared with low-volume centers $\left(6.1 \%\right.$ vs $12.9 \%$, p < 0.001). ${ }^{11}$

\section{Strengths and Limitations}

To the best of our knowledge this is the first study in the literature in which the postoperative morbidity and 
mortality rates in patients undergoing temporal lobectomy for epilepsy have been investigated using a national surgical registry. In comparison with previous studies based on administrative databases, which are populated by billing data and contain details only for the inpatient course, we provide insight into the associated outcomes in the 30-day postoperative period with a level of resolution closer to that seen in single-institution studies. Moreover, the use of CPT codes in the NSQIP allowed for precise sampling of patients who underwent temporal lobe surgery, whereas older studies used ICD-9 procedure codes, ${ }^{13}$ which are not specific to the resected brain region. Last, the NSQIP offers a superior level of detail regarding perioperative complications compared with administrative databases, as demonstrated by previous articles. ${ }^{12,20}$ Nevertheless, the results of our study need validation by similar large-scale studies conducted in national databases, such as the University HealthSystem Consortium and Optum Labs. More importantly, the creation of a surgical registry for patients with refractory epilepsy is of paramount importance for tracking surgical and patient-reported outcomes in the current health care reform era.

Our study has several inherent limitations as well. First of all, the study was retrospective in nature and, as with all registry studies, there is a risk of selection and coding bias. The sample size was relatively small for the number of years included, which can be attributed to the NSQIP's stratified sampling frame and the relatively lower number of epilepsy cases compared with other surgical interventions. The NSQIP also does not contain a hospital identifier variable, and therefore we could not incorporate hospital volume or type (i.e., private vs academic) into our analysis and investigate the association between these variables and postoperative outcomes. However, in light of the fact that the majority of the participating institutions are large academic centers, we hypothesize that specialized epilepsy centers contributed most of the cases in the current study. Moreover, the NSQIP, like other national databases, lacks important clinical variables including underlying pathology, because there is no ICD-9 code to differentiate between the pathophysiologies leading to intractable epilepsy. Therefore, we could not correlate the underlying pathology with the risk of the study's end points. Last, we were limited to the 30-day postoperative window and therefore we cannot provide insight into the long-term functional outcomes, seizure control, or ASM use postoperatively.

\section{Conclusions}

In the present study, we sought to establish national benchmarks of 30-day postoperative complications after temporal lobectomy for TLE by using a national surgical registry. Increasing patient age was a significant predictor of discharge to a location other than home. Moreover, the presence of an attending neurosurgeon and a resident during the procedure was significantly associated with shorter hospital stays and discharge disposition. Although the technique has been performed in the US for more than 65 years ${ }^{2,28}$ and is generally safe, perioperative mortality can be as high as $1.4 \%$. Neurosurgeons should be cognizant of the complications in the immediate postoperative period and tailor their decision making in higher-risk patients accordingly.

\section{Acknowledgments}

We thank Dr. Che Ngufor, $\mathrm{PhD}$, for his help with the statistical analysis of the manuscript. This publication was made possible by funding from the Mayo Clinic Robert D. and Patricia E. Kern Center for the Science of Health Care Delivery.

\section{References}

1. American College of Surgeons: User Guide for the 2014 ACS NSQIP Participant Use Data File (PUF). (https:// www.facs.org/ /media/files/quality\%20 programs/nsqip/ nsqip_puf_userguide_2014.ashx) [Accessed March 2, 2017]

2. Bailey P, Gibbs FA: The surgical treatment of psychomotor epilepsy. J Am Med Assoc 145:365-370, 1951

3. Benbadis SR: Is the underlying cause of epilepsy a major prognostic factor for recurrence? Neurology 53:440, 1999

4. Breiman L: Random forests. Mach Learn 45:5-32, 2001

5. Duncan JS, Sander JW, Sisodiya SM, Walker MC: Adult epilepsy. Lancet 367:1087-1100, 2006

6. Engel J Jr: Another good reason to consider surgical treatment for epilepsy more often and sooner. Arch Neurol 68:707-708, 2011

7. Engel J Jr: Mesial temporal lobe epilepsy: what have we learned? Neuroscientist 7:340-352, 2001

8. Engel J Jr, McDermott MP, Wiebe S, Langfitt JT, Stern JM, Dewar S, et al: Early surgical therapy for drug-resistant temporal lobe epilepsy: a randomized trial. JAMA 307:922-930, 2012

9. Engel J Jr, Wiebe S, French J, Sperling M, Williamson P, Spencer D, et al: Practice parameter: temporal lobe and localized neocortical resections for epilepsy: report of the Quality Standards Subcommittee of the American Academy of Neurology, in association with the American Epilepsy Society and the American Association of Neurological Surgeons. Neurology 60:538-547, 2003

10. Englot DJ, Ouyang D, Garcia PA, Barbaro NM, Chang EF: Epilepsy surgery trends in the United States, 1990-2008. Neurology 78:1200-1206, 2012

11. Englot DJ, Ouyang D, Wang DD, Rolston JD, Garcia PA, Chang EF: Relationship between hospital surgical volume, lobectomy rates, and adverse perioperative events at US epilepsy centers. J Neurosurg 118:169-174, 2013

12. Enomoto LM, Hollenbeak CS, Bhayani NH, Dillon PW, Gusani NJ: Measuring surgical quality: a national clinical registry versus administrative claims data. J Gastrointest Surg 18:1416-1422, 2014

13. Faciszewski T, Jensen R, Berg RL: Procedural coding of spinal surgeries (CPT-4 versus ICD-9-CM) and decisions regarding standards: a multicenter study. Spine (Phila Pa 1976) 28:502-507, 2003

14. Georgiadis I, Kapsalaki EZ, Fountas KN: Temporal lobe resective surgery for medically intractable epilepsy: a review of complications and side effects. Epilepsy Res Treat 2013:752195, 2013

15. Grivas A, Schramm J, Kral T, von Lehe M, Helmstaedter C, Elger CE, et al: Surgical treatment for refractory temporal lobe epilepsy in the elderly: seizure outcome and neuropsychological sequels compared with a younger cohort. Epilepsia 47:1364-1372, 2006

16. Hader WJ, Tellez-Zenteno J, Metcalfe A, Hernandez-Ronquillo L, Wiebe S, Kwon CS, et al: Complications of epilepsy surgery: a systematic review of focal surgical resections and invasive EEG monitoring. Epilepsia 54:840-847, 2013

17. Kale R: Bringing epilepsy out of the shadows. BMJ 315:2-3, 1997 
18. Kerezoudis P, McCutcheon BA, Murphy M, Rayan T, Gilder $\mathrm{H}$, Rinaldo L, et al: Predictors of 30-day perioperative morbidity and mortality of unruptured intracranial aneurysm surgery. Clin Neurol Neurosurg 149:75-80, 2016

19. Koubeissi MZ, Puwanant A, Jehi L, Alshekhlee A: In-hospital complications of epilepsy surgery: a six-year nationwide experience. Br J Neurosurg 23:524-529, 2009

20. Lawson EH, Louie R, Zingmond DS, Brook RH, Hall BL, Han L, et al: A comparison of clinical registry versus administrative claims data for reporting of 30-day surgical complications. Ann Surg 256:973-981, 2012

21. McClelland S III, Guo H, Okuyemi KS: Population-based analysis of morbidity and mortality following surgery for intractable temporal lobe epilepsy in the United States. Arch Neurol 68:725-729, 2011

22. McClelland S III, Guo H, Okuyemi KS: Racial disparities in the surgical management of intractable temporal lobe epilepsy in the United States: a population-based analysis. Arch Neurol 67:577-583, 2010

23. McCutcheon BA, Kerezoudis P, Porter AL, Rinaldo L, Murphy M, Maloney P, et al: Coma and stroke following surgical treatment of unruptured intracranial aneurysm: an American College of Surgeons National Surgical Quality Improvement Program study. World Neurosurg 91:272-278, 2016

24. McCutcheon BA, Ubl DS, Babu M, Maloney P, Murphy M, Kerezoudis P, et al: Predictors of surgical site infection following craniotomy for intracranial neoplasms: an analysis of prospectively collected data in the American College of Surgeons National Surgical Quality Improvement Program Database. World Neurosurg 88:350-358, 2016

25. Missios S, Kalakoti P, Nanda A, Bekelis K: Craniotomy for glioma resection: a predictive model. World Neurosurg 83:957-964, 2015

26. Murphy M, Gilder H, McCutcheon BA, Kerezoudis P, Rinaldo L, Shepherd D, et al: Increased operative time for benign cranial nerve tumor resection correlates with increased morbidity postoperatively. J Neurol Surg B Skull Base 77:350 357, 2016

27. Murray CJL, López AD, Jamison DT: The global burden of disease in 1990: summary results, sensitivity analysis and future directions. Bull World Health Organ 72:495-509, 1994

28. Penfield W, Baldwin M: Temporal lobe seizures and the technic of subtotal temporal lobectomy. Ann Surg 136:625-634, 1952

29. Pitt HA, Kilbane M, Strasberg SM, Pawlik TM, Dixon E, Zyromski NJ, et al: ACS-NSQIP has the potential to create an HPB-NSQIP option. HPB (Oxford) 11:405-413, 2009
30. Salanova V, Markand O, Worth R: Temporal lobe epilepsy surgery: outcome, complications, and late mortality rate in 215 patients. Epilepsia 43:170-174, 2002

31. Schiltz NK, Koroukian SM, Lhatoo SD, Kaiboriboon K: Temporal trends in pre-surgical evaluations and epilepsy surgery in the U.S. from 1998 to 2009. Epilepsy Res 103:270278,2013

32. Spencer SS, Berg AT, Vickrey BG, Sperling MR, Bazil CW, Shinnar S, et al: Initial outcomes in the Multicenter Study of Epilepsy Surgery. Neurology 61:1680-1685, 2003

33. Sperling MR, Barshow S, Nei M, Asadi-Pooya AA: A reappraisal of mortality after epilepsy surgery. Neurology 86:1938-1944, 2016

34. Sperling MR, Feldman H, Kinman J, Liporace JD, O'Connor MJ: Seizure control and mortality in epilepsy. Ann Neurol 46:45-50, 1999

35. Stekhoven DJ, Bühlmann P: MissForest-non-parametric missing value imputation for mixed-type data. Bioinformatics 28:112-118, 2012

36. Van Gompel JJ, Ottman R, Worrell GA, Marsh R, Wetjen NM, Cascino GD, et al: Use of anterior temporal lobectomy for epilepsy in a community-based population. Arch Neurol 69:1476-1481, 2012

37. Wiebe S, Blume WT, Girvin JP, Eliasziw M: A randomized, controlled trial of surgery for temporal-lobe epilepsy. $\mathbf{N}$ Engl J Med 345:311-318, 2001

\section{Disclosures}

The authors report no conflict of interest concerning the materials or methods used in this study or the findings specified in this paper.

\section{Author Contributions}

Conception and design: Kerezoudis. Acquisition of data: Kerezoudis. Analysis and interpretation of data: Kerezoudis. Drafting the article: Kerezoudis. Critically revising the article: Bydon, Kerezoudis, Murphy, Rajjoub, Ubl. Reviewed submitted version of manuscript: Bydon, McCutcheon, Murphy, Rajjoub, Habermann, Worrell, Van Gompel. Statistical analysis: Kerezoudis, Ubl, Van Gompel. Study supervision: Habermann, Worrell, Van Gompel.

\section{Correspondence}

Mohamad Bydon, Department of Neurosurgery, Mayo Clinic, 200 First Street SW, Rochester, MN 55905. email: bydon.mohamad@ mayo.edu. 